\title{
A New Synthetic Route to (S)-Chroman Aldehyde, a Key Chiral Precursor of Vitamin E
}

\author{
Hisashi Mikoshiba, Koichi Mikami, Takeshi Nakai* \\ Department of Chemical Technology, Tokyo Institute of Technology, Meguro-ku, Tokyo 152-8552, Japan \\ Fax +81-(0)3-5734-2885; E-mail: takeshi@ o.cc.titech.ac.jp \\ Received 30 January 2001 \\ Dedicated with honor to Prof. Ryoji Noyori
}

\begin{abstract}
A highly stereocontrolled synthetic route to $(S)$-chroman aldehyde has been developed which starts with trimethyl- $p$-hydroquinone and $(R)$-glycerladehyde acetonide and employs as key steps the Michael addition of the aromatic copper species onto the $(R)$-4-acryloyl-1,3-dioxolane followed by the highly diastereoselective methylation of the resulting ketone adduct.
\end{abstract}

Key words: chroman aldehyde, diastereoselectivity, glycerketone, Michael addition, vitamin E

In recent years considerable effort has been devoted to the development of efficient methods for the asymmetric synthesis of vitamin $E$ ( $\alpha$-tocopherol) and its key intermediate, $(S)$-chroman aldehyde (1). ${ }^{1,2}$ The most crucial problem in their syntheses is associated with the stereoselective creation of the "quaternary" chiral center in the chroman ring (or its tert-alcoholic precursor). While we have recently developed a highly diastereoselective protocol for the methylation of "glycerketone acetonides" (4acyl-2,2-dimethyl-1,3-oxolanes) which affords the tertiary alcohols (terpenetriols) in enantiopure form, ${ }^{3}$ we became interested in developing a new synthetic route to the vitamin E precursor $(S)$-1 by applying our "glycerketone's methylation protocol" as a key stereocontrolling step. Our synthetic plan is depicted in Scheme 1. For the preparation of the requisite "glycerketone" $\mathbf{4}$, routes $\mathbf{a}$ and $\mathbf{b}$ are available. Apparently, route $\mathbf{a}$ is more convergent and efficient than route $\mathbf{b}$, since bromide $\mathbf{6}$ required as the organometallic precursor for the former is more easily accessible than bromide 6' for the latter. ${ }^{4}$ We now wish to report the successful realization of the synthetic plan to eventually furnish $(S)$-chroman aldehyde (1) in enantiopure form and relatively high overall yield.

Our synthesis began with the preparation of the aromatic bromide 6 required for generating the organometallic species. Thus, trimethyl-p-hydroquinone (8) was methylated with dimethyl sulfate $\left[(n-\mathrm{Bu})_{4} \mathrm{NI}\right.$, aq. $\mathrm{KOH}$, r.t.] followed by bromination $\left(\mathrm{Br}_{2}, \mathrm{CCl}_{4}, 0{ }^{\circ} \mathrm{C}\right)$ to give bromide $6^{2 \mathrm{i}}$ in almost quantitative yield. On the other hand, the requisite vinyl ketone (4-acryloyl-1,3-dioxolane) $\mathbf{5}$ was prepared from the commercially available $(R)$-aldehyde 7 in $>95 \%$ overall yield via the reaction with vinylmagnesium bromide and the Swern oxidation of the resulting alcohol [DMSO, $\left.(\mathrm{COCl})_{2}, \mathrm{TEA},-70{ }^{\circ} \mathrm{C}\right] .{ }^{5,6} \mathrm{It}$ is interesting to note that vinyl ketone $\mathbf{5}$ is rather stable enough to be isolated by flash column chromatography. Next, we carried out the
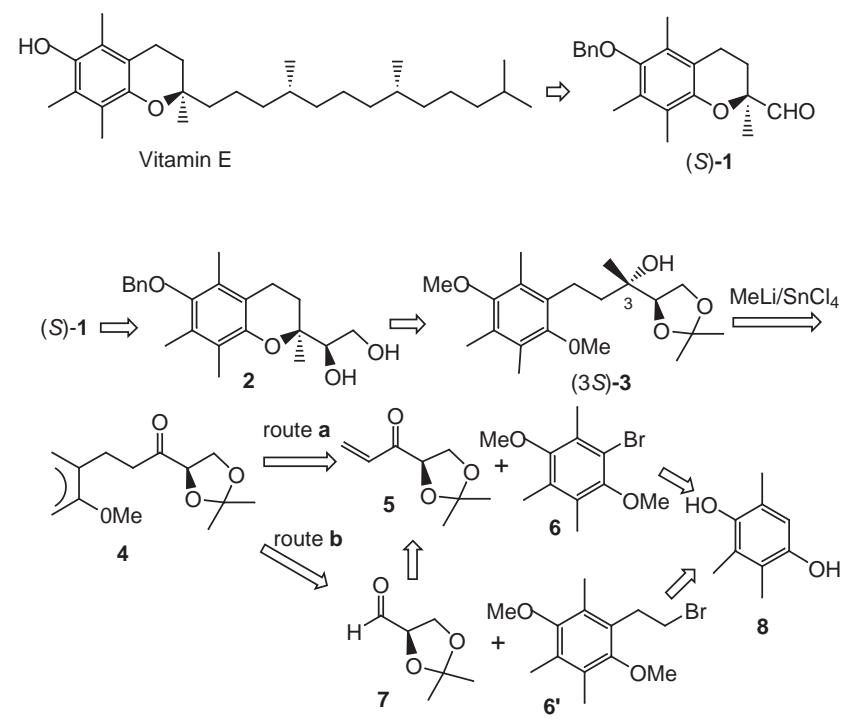

Scheme 1

Michael addition reaction of the Grignard reagent generated from bromide $6\left[\mathrm{Mg}\right.$ (2.0 equiv), $\left(\mathrm{CH}_{2} \mathrm{Br}\right)_{2}(1.0$ equiv), THF, reflux] onto vinyl ketone 5 in the presence of $\mathrm{CuI}$ and $\mathrm{Me}_{3} \mathrm{SiCl}$ in THF/HMPA at $-70{ }^{\circ} \mathrm{C}$ to give the desired ketone 4 in $64 \%$ isolated yield. ${ }^{7}$ Interestingly, the absence of $\mathrm{Me}_{3} \mathrm{SiCl}$ led to a lower yield (39\%). The next step is the stereochemically crucial methylation of ketone 4 using our recently-reported protocol. ${ }^{3}$ Thus, ketone 4 was treated with an excess of $\mathrm{MeLi} / \mathrm{SnCl}_{4}$ complex in dichloromethane at $-70{ }^{\circ} \mathrm{C}$ to give the tert-alcohol 3 with high diastereomeric ratio (94: 6) in quantitative yield. The ${ }^{1} \mathrm{H}$ NMR spectrum $\left(\mathrm{CDCl}_{3}\right)$ of $\mathbf{3}$ showed two peaks due to 3 -Me at $\delta 1.33$ for the major and $\delta 1.20$ for the minor. ${ }^{8}$ The major product was assigned to the desired $(3 S)$-isomer by analogy with the NMR data reported for the epimeric pairs of the closely related triol acetonides. ${ }^{3}$

With the highly enantio-enriched (3S)-alcohol $\mathbf{3}$ in hand, further effort was directed to its transformation into the target aldehyde $\mathbf{1}$ (Scheme 2). Thus, alcohol $\mathbf{3}$ was treated with the cerium ammonium salt following the reported procedure $^{2 \mathrm{i}}$ to give the quinone form $9 .{ }^{9}$ Acid treatment of 9 gave the cyclized intermediate as crystals and its recrystallization from ethanol gave the stereochemically pure compound in $94 \%$ yield. Then, the intermediate was hydrogenated to afford the chroman derivative $10 .{ }^{10}$ It 
should be noted that the original $(3 S)$-chirality in alcohol $\mathbf{3}$ is completely retained on the chroman ring of $\mathbf{1 0}$. After re-protections of the diol moiety as the acetonide and the phenolic hydroxy group as the benzyl ether, the resulting intermediate $11^{11}$ was subjected to oxidative cleavage to furnish $(R)$-aldehyde 1 in enantiopure form and $83 \%$ overall yield from alcohol 3; mp 50-52 ${ }^{\circ} \mathrm{C} ;[\alpha]_{\mathrm{D}}+11.9\left(\mathrm{CHCl}_{3}\right.$, $\left.c=1.66,18^{\circ} \mathrm{C}\right)$. The physical data were in agreement with the literature values, and the ${ }^{1} \mathrm{H}$ NMR spectral data are also in accord with the reported ones. ${ }^{1 b, 12}$ LIS-NMR analysis using $\mathrm{Eu}(\mathrm{hfc})_{3}{ }^{2 \mathrm{e}, \mathrm{g}}$ confirmed that aldehyde $(S)-\mathbf{1}$ is enantiomerically pure.

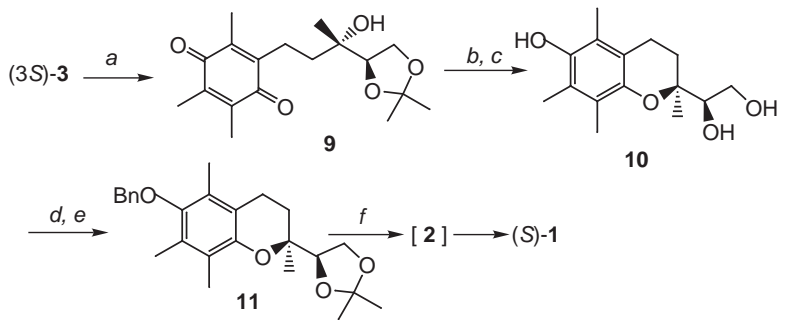

Scheme 2 Reagents: (a) $\mathrm{Ce}\left(\mathrm{NH}_{4}\right)_{2}\left(\mathrm{NO}_{3}\right)_{6}, \mathrm{MeCN}$ (100\%); (b) $\mathrm{HCl}$, aq. $\mathrm{MeOH}(96 \%)$; (c) $\mathrm{H}_{2}, \mathrm{Pd} / \mathrm{C}, \mathrm{EtOH}(100 \%)$; (d) $\mathrm{Me}_{2} \mathrm{C}(\mathrm{OMe})_{2}$, PT$\mathrm{SA}, \mathrm{Et}_{2} \mathrm{O}\left(94 \%\right.$ ); (e) $\mathrm{BnBr}, \mathrm{K}_{2} \mathrm{CO}_{3}$, $\mathrm{DMF}\left(99 \%\right.$ ); (f) $\mathrm{H}_{5} \mathrm{IO}_{6}$, aq. THF (99\%).

In summary, we have developed a new, short synthetic route to $(R)$-chroman aldehyde $(\mathbf{1})$, a key chiral precursor of vitamin $\mathrm{E}$ from commercially available trimethyl- $p$-hydroquinone and $(R)$-glycerladehyde acetonide. This synthesis highlights the use of the Michael addition to introduce the aromatic part into the chiral aliphatic framework and the use of our methylation protocol to create the crucial "quaternary" chirality in high diastereoselectivity. Thus, this route seems to be attractive for the practical asymmetric synthesis of vitamin $\mathrm{E}$.

\section{References and Notes}

(1) For asymmetric synthesis of vitamin E, see, e.g.: (a) Olson, L.; Cheung, H.-C.; Morgan, K.; Saucy, G. J. Org. Chem. 1980, 45, 803. (b) Cohen, N.; Lopresti, R. J.; Saucy, G. J. Am. Chem. Soc. 1979, 101, 6710.

(2) For selected asymmetric synthesis of $(R)$-chroman aldehyde $\mathbf{1}$ (or synthetic equivalents), see: (a) Tietze, L. F.; Görlitzer, J. Synlett 1996, 1041. (b) Mizuguchi, E.; Achiwa, K. Synlett 1995, 1255. (c) Takano, S.; Yoshimitsu, T.; Ogasawara, K. Synlett 1990, 451 (1990). (d) G. Solladie, G.; Moine, G. J. Am. Chem. Soc. 1984, 106, 6097. (e) Takabe, K.; Okisaka, K.;

Uchiyama, Y.; Katagiri, T.; Yoda, H. Chem. Lett. 1985, 561. (f) Fuganti, C.; Grasselli, P. J. Chem. Soc., Chem. Commun. 1982, 205. (g) Sakito, Y.; Suzukamo, G. Tetrahedron Lett. 1982, 23, 4953. (h) Cohen, N.; Lopresti, R. J.; Neukom, C. J. Org. Chem. 1981, 46, 2445. (i) Barner, R.; M. Schmid, M. Helv. Chim. Acta 1979, 62, 2384.

(3) Mikoshiba, H.; Mikami, K.; Nakai, T. Heterocycles 2001, in press.

(4) In fact, the reported synthetic method for the precursors of bromide 6' requires seven steps from 8: Smith, L. I.; Maullen, C. W. J. Am. Chem. Soc. 1936, 58, 629.

(5) Vinyl ketone 5: $[\alpha]_{\mathrm{D}}+83.5^{\circ}\left(\mathrm{CHCl}_{3}, c=2.06,19^{\circ} \mathrm{C}\right)$; ${ }^{1} \mathrm{H}$ NMR $\left(\mathrm{CDCl}_{3}\right), \delta 1.42(\mathrm{~s}, 3 \mathrm{H}), 1.47(\mathrm{~s}, 3 \mathrm{H}), 3.96-4.37(\mathrm{~m}$, $2 \mathrm{H}), 4.63(\mathrm{t}, 1 \mathrm{H}), 5.86(\mathrm{dd}, 1 \mathrm{H}, \mathrm{J}=1.8,11.6 \mathrm{~Hz}), 6.40(\mathrm{dd}, 1 \mathrm{H}$, $\mathrm{J}=1.8,17.4 \mathrm{~Hz}), 6.83(\mathrm{dd}, 1 \mathrm{H}, \mathrm{J}=11.6,17.4 \mathrm{~Hz})$.

(6) The attempted oxidation of the allylic alcohol with PCC failed, while the oxidation with $\mathrm{MnO}_{2}$ gave ketone 5 in ca. $30 \%$ yield.

(7) Ketone 4: $[\alpha]_{\mathrm{D}}+29.3^{\circ}\left(\mathrm{CHCl}_{3}, c=1.92,20{ }^{\circ} \mathrm{C}\right) ;{ }^{1} \mathrm{H}$ NMR $\left(\mathrm{CDCl}_{3}\right), \delta 1.37(\mathrm{~s}, 3 \mathrm{H}), 1.47(\mathrm{~s}, 3 \mathrm{H}), 2.17(\mathrm{~s}, 6 \mathrm{H}), 2.20(\mathrm{~s}$ $3 \mathrm{H}), 2.83(\mathrm{t}, 4 \mathrm{H}, \mathrm{J}=3.0 \mathrm{~Hz}), 3.35(\mathrm{~s}, 6 \mathrm{H}), 3.97(\mathrm{dd}, 1 \mathrm{H}$, $\mathrm{J}=6.0,6.8 \mathrm{~Hz}), 4.17(\mathrm{dd}, 1 \mathrm{H}, \mathrm{J}=6.8,6.8 \mathrm{~Hz}), 4.43(\mathrm{dd}, 1 \mathrm{H}$, $\mathrm{J}=6.0,6.8 \mathrm{~Hz}$ )

(8) The major isomer of alcohol 3: ${ }^{1} \mathrm{H} \mathrm{NMR}\left(\mathrm{CDCl}_{3}\right), \delta 1.33(\mathrm{~s}$, $3 \mathrm{H}), 1.37(\mathrm{~s}, 3 \mathrm{H}), 1.43(\mathrm{~s}, 3 \mathrm{H}), 2.17(\mathrm{~s}, 6 \mathrm{H}), 2.23(\mathrm{~s}, 3 \mathrm{H}), 2.53$ $3.00(\mathrm{~m} 4 \mathrm{H}), 3.63(\mathrm{~s}, 3 \mathrm{H}), 3.68(\mathrm{~s}, 3 \mathrm{H}), 3.68(\mathrm{~s}, 3 \mathrm{H}), 3.83-4.17$ $(\mathrm{m}, 3 \mathrm{H})$.

(9) Quinone 9: IR (neat), $1640 \mathrm{~cm}^{-1}(\mathrm{C}=\mathrm{O}) ;[\alpha]_{\mathrm{D}}+13.5^{\circ}\left(\mathrm{CHCl}_{3}\right.$, $\left.c=0.56,20^{\circ} \mathrm{C}\right) ;{ }^{1} \mathrm{H}$ NMR $\left(\mathrm{CDCl}_{3}\right), \delta 1.27(\mathrm{~s}, 3 \mathrm{H}), 1.33(\mathrm{~s}$, $3 \mathrm{H}), 1.40(\mathrm{~s}, 3 \mathrm{H}), 1.43-1.80(\mathrm{~m}, 2 \mathrm{H}), 1.97(\mathrm{~s}, 6 \mathrm{H}), 2.03(\mathrm{~s}$, $3 \mathrm{H}), 2.17$ (br, s, 1H), 2.37-2.83 (m, 2H), 3.77-4.10 (m, 3H).

(10) Diol 10: $[\alpha]_{\mathrm{D}}-5.4^{\circ}\left(\mathrm{MeOH}, c=0.88,19^{\circ} \mathrm{C}\right) ;{ }^{1} \mathrm{H}$ NMR $\left(\right.$ DMSO- $\left.d_{6}\right), \delta 1.10(\mathrm{~s}, 3 \mathrm{H}), 1.75(\mathrm{t}, 2 \mathrm{H}, \mathrm{J}=6.8 \mathrm{~Hz}), 2.00(\mathrm{~s}$, $3 \mathrm{H}), 2.03(\mathrm{~s}, 3 \mathrm{H}), 2.06(\mathrm{~s}, 3 \mathrm{H}), 2.27-2.73(\mathrm{t}, 2 \mathrm{H}, \mathrm{J}=6.8 \mathrm{~Hz})$, 4.20-4.43 (m, 2H), 4.73-4.90 (m, 1H), $7.37(\mathrm{~s}, 1 \mathrm{H})$.

(11) Intermediate 11: $\mathrm{mp}, 105-107^{\circ} \mathrm{C} ;[\alpha]_{\mathrm{D}}+55.0^{\circ}\left(\mathrm{CHCl}_{3}\right.$, $\left.c=0.39,22{ }^{\circ} \mathrm{C}\right) ;{ }^{1} \mathrm{H}$ NMR $\left(\mathrm{CDCl}_{3}\right), \delta 1.20(\mathrm{~s}, 3 \mathrm{H}), 1.37(\mathrm{~s}$, $3 \mathrm{H}), 1.47(\mathrm{~s}, 3 \mathrm{H}), 1.87(\mathrm{t}, 2 \mathrm{H}, \mathrm{J}=6.8 \mathrm{~Hz}), 2.07(\mathrm{~s}, 3 \mathrm{H}), 2.13$ $(\mathrm{s}, 3 \mathrm{H}), 2.20(\mathrm{~s}, 3 \mathrm{H}), 2.63(\mathrm{t}, 2 \mathrm{H}, \mathrm{J}=6.8 \mathrm{~Hz}), 3.87-4.33(\mathrm{~m}$, $3 \mathrm{H}), 4.07(\mathrm{~s}, 2 \mathrm{H}), 7.27-7.57(\mathrm{~m}, 5 \mathrm{H})$.

(12) Aldehyde (S)-1: ${ }^{1} \mathrm{H}$ NMR $\left(\mathrm{CDCl}_{3}\right), \delta 1.40(\mathrm{~s}, 3 \mathrm{H}), 1.77(\mathrm{t}, 2 \mathrm{H}$, $\mathrm{J}=6.8 \mathrm{~Hz}), 2.10(\mathrm{~s}, 3 \mathrm{H}), 2.17(\mathrm{~s}, 3 \mathrm{H}), 2.23(\mathrm{~s}, 3 \mathrm{H}), 2.57(\mathrm{t}, 2 \mathrm{H}$, $\mathrm{J}=6.8 \mathrm{~Hz}), 4.70(\mathrm{~s}, 2 \mathrm{H}), 7.24-7.63(\mathrm{~m}, 5 \mathrm{H}), 9.60(\mathrm{~s}, 1 \mathrm{H})$.

Article Identifier:

1437-2096,E;2001,0,SI,0989,0990,ftx,en;Y03601ST.pdf 